Revista Iberoamericana. Vol. LXIII, Núms. 178-179, Enero-Junio 1997; 185-192

\title{
MEJOR SE DUERME EN LA PAMPA. DESEO Y NATURALEZA EN UNA EXCURSIÓN A LOS INDIOS RANQUELES DE LUCIO V. MANSILLA
}

\author{
POR \\ Cristina Iglesia \\ Universidad de Buenos Aires, Argentina
}

La autobiografia es el gran género del siglo XIX. En la Argentina -donde casi ningún hombre con actuación pública dejó de frecuentarlo- el caso de Mansilla se recorta de ese vasto corpus autobiográfico.

Una excursión a los indios ranqueles es el primer y quizás único ejemplo de folletín autobiográfico en la literatura argentina. Este injerto feliz y espectacular de dos géneros decimonónicos inicia una serie en la obra de Mansilla. Desde la publicación de Ranqueles (que aparece por entregas en el diario La Tribuna entre mayo y noviembre de 1870 y que inmediatamente, antes de terminar el año, se convierte en libro), la conjunción del efecto autobiográfico y el ritmo folletinesco será la marca de su estética hasta 1888 , cuando el períodico Sud América publique las Causeries de los jueves, esta vez con un ritmo semanal.

Ranqueles constituye, junto con las Causeries, el corpus más significativo de su obra: el proyecto central de Mansilla consiste, pues, en convertir su vida en literatura por entregas. Cada semana, el lector podrá enterarse alternativamente, de sus aventuras entre los ranqueles - Mansilla vuelve varias veces a este primer viaje en las Causeries - o saber más sobre sus vicios ocultos, sobre sus amores de juventud, sobre su madre (hermana de Rosas) sobre su padre (general de Rosas) sobre Rosas mismo, aunque sea a partir de una parte ínfima de su cuerpo como en la pequeña historia, "El dedo de Rozas". Cada semana el escritor se reencontrará con un publico adicto, goloso, que paladea esa manera de practicar la literatura que combina sabiamente la amenidad, la frivolidad y la audacia.

Ranqueles relata un viaje a caballo hacia los indios. Casi veinte años después, en una de sus causeries más conocidas, "Los siete platos de arroz con leche" (una de las más conocidas, creo, porque lleva en su título el nombre del postre más criollo y más infantil, y esto lo vuelve, se supone, un texto apto para antologías escolares) se relata otro viaje a caballo, esta vez desde el centro de la ciudad hasta sus alrededores, hacia sus quintas, hacia "la" quinta de Palermo, la cueva de Rosas, la cueva del dictador. Ambos viajes reúnen así los polos del imaginario liberal sobre la barbarie: por un lado, la barbarie rural, de la que el indio es la figura central, y por el otro, la barbarie más temida, la entronizada en las ciudades en círculos concéntricos que rodean la esfinge de Rosas. Se trata de viajes descentrados, que se dirigen a dos exotismos cercanos y de diversa peligrosidad pero igualmente enigmáticos.

En ambos textos, la "filosofía del éxito del escándalo" que Mansilla practica cuando escribe y cuando actúa, vincula, como propuesta estética, una serie de cuestiones alrededor 
del relato autobiográfico, como por ejemplo, desde dónde y hacia dónde viajar y en qué género o mezcla de géneros producir el relato de viaje que es, a la vez, relato de vida.

\section{El SUEÑo DEL VIAJE}

En Ranqueles, Mansilla propone un desafio: narrar un demorado viaje a caballo exactamente en el momento en que la novela y la literatura de viajes se han apoderado del ferrocarril y del vapor para acelerar el pulso de sus lectores. Escribir el relato de un viaje hacia un lugar donde "sólo se puede entrar a caballo". Mientras los relatos de otros viajeros disfrutan y explotan los medios de transporte de la modernidad (a esa altura del siglo los relatos se están moviendo aceleradamente) Mansilla elige la demorada marcha de los caballos.

El viaje de Sarmiento por Estados Unidos describe el asombro y el entusiasmo que le despierta ese "pueblo en viaje" o "país en movimiento"; imágenes simétricas con las que nombra a los americanos del norte. En sus imágenes no sólo la vida económica de este país moderno se articula sobre un proyecto de viaje en tren o vapor sino que, hasta las zonas de mayor intimidad de la vida cotidiana tienen que ver con los viajes, que definen también el carácter de sus ciudadanos: "Atribuyo pues a aquellos amores ambulantes en que termina el flirteo americano la manía de viajar que distingue al yanqui, de quien puede decirse que nace viajero". E insiste: "Volviendo pues, a los millares de novios que andan enardeciendo y vivificando la atmósfera con sus hálitos de primavera, debo decir que los vapores del Hudson y los de otros ríos clásicos les tienen preparados departamentos ad-hoc: llámase este recinto "cámara de la novia"'. En esa cámara nupcial Sarmiento reúne casi todos los elementos del lujo y el confort modernos. La suntuosa y elegante cámara de los novios se desliza en un barco, sobre las aguas. Con la modernidad, todo lo que hay de acogedor en la civilización puede transportarse, parece afirmar Sarmiento.

En el extremo opuesto, al iniciar su excursión, Mansilla se despoja de los enseres de la civilización. Escribe: "Cuando yo me dispongo a una correría sólo una cosa me importa, los caballos".

Sabemos cómo imagina Sarmiento a los caballos: son la máquina de guerra de la montonera. Los caballos, en la escritura de Sarmiento, están siempre en movimiento para impedir el avance de la civilización. Una y otra vez, viñedos en Mendoza, sembradíos en San Juan son destruídos por el paso de los caballos, que el lector de Sarmiento, debe adscribir, decididamente, al bando federal.

Mansilla, que ya ha disfrutado del viaje en barco y en tren, elige un viaje a caballo para entretener a sus lectores y competir con exotismos más lejanos y refinados que plantean los itinerarios contemporáneos, realizados con artefactos de transporte más sofisticados o singulares.

Mansilla no importa ni exotismos ni medios de transportes: en Ranqueles, todo es, a la vez, cercano y lejano, conocido y desconocido, estimulante y amenazador. Los polos de las oposiciones también operan simultáneamente sobre el lector en "Los siete platos de arroz con leche".

La escritura de Mansilla convierte en exóticos dos elementos difíciles de incorporar de otro modo. Uno, del presente: los indios; y otro, del pasado reciente: Rosas. Rosas es un 
indio, dice David Viñas en Indios, ejército y fronteras, y éste es el lugar exacto que tienen para Mansilla estas dos palabras que incomodan porque funcionan como polos amenazadores en la serie bárbara del imaginario liberal. Al producir este movimiento de incorporación, Mansilla muestra que es el único capaz de narrar esos dos polos: conozco a los indios porque estuve entre ellos y fui como ellos del mismo modo que "soy el único hombre de letras en este país que sabe bien a Rozas".

Él es una "lengua de contacto" frente a ambos polos de la amenaza bárbara. Mansilla es el gran lenguaraz, la lengua contacto de la literatura argentina del siglo XIX porque parece posibilitar las traducciones necesarias cada vez que se instala una frontera histórica $o$ cultural.

\section{Mejor SE DUERME EN LA PAMPA}

Una excursión a los indios ranqueles es el folletín de un viajero o un viaje por entregas cuyo centro es el viajero mismo. Mientras avanza hacia los indios, el texto, el viajero, incorporará otros relatos a la expedición: son relatos de y para hombres, que narran amores contrariados y protestan injusticias. En el momento privilegiado del fogón, cuando la marcha se detiene, la reunión de los relatos alrededor del fuego convoca los recuerdos, fantasías y sueños de quienes viajan hacia un destino incierto.

Estas historias enlazadas por el fogón, en las pausas de la expedición o contadas sobre el andar al paso de los caballos, sostienen el interés del lector, hacen que vuelva a buscar la página del folletín en el diario. Pero lo asombroso es de qué modo el escritor sostiene día tras día la atención de sus lectores en los momentos en que no se incorporan relatos, ni hay encuentros con indios, ni sucede alguna cosa que merezca contarse: Mansilla narra el avance de la expedición, demorando las llegadas, no sólo para incorporar relatos, sino para contar algo tan simple y tan difícil como el puro desplazamiento de unos hombres a caballo en el espacio inmóvil de la pampa.

Las zonas del viaje en las que parece no pasar nada están notablemente expandidas. Mientras sus compañeros de viaje duermen, él escribe: "sea lo que fuere yo digo que viajando por los campos en una noche clara es un placer dormir. Por mi parte, al tranco, al trote o al galope, yo duermo perfectamente. Y no sólo duermo sino que sueño". Cuando Mansilla afirma "mejor se duerme en la pampa", coloca el lomo del caballo exactamente en el extremo opuesto del hotel, el lugar convencional que la ciudad ofrece para que el viajero descanse bajo techo del campo abierto.

Mejor se duerme en la pampa, porque con el andar del caballo no solamente duermo, también sueño. La expedición militar que va a cumplir una misión semioficial ha sido ya desplazada por el placer del viaje a cielo descubierto.

En este mismo sentido puede leerse la carta a Racedo fechada en El Cuero el segundo día de la excursión, en la que Mansilla se detiene a relatar: "Ayer se deslomó una mula y la manducamos. La felicidad no es una quimera. Hay que atraparla por los cabellos".

Mansilla se constituye en un sujeto en estado de naturaleza. Al suscitar en el lector la sensación de viajar paso a paso con quien escribe, provoca también el deseo del lector de estar en el lomo de su caballo, en una noche abierta, soñando. Es decir, logra producir en quien lo lee el deseo de algo tan simple y tan cercano para un habitante de las ciudades del 
siglo XIX como andar a caballo por las noches. Al acompañar el movimiento de Mansilla y de su tropa, el que lee se ve obligado a cambiar de perspectiva. Siente, como Mansilla escribe, que en ese momento, en el desierto no hay peligro: "En todo pensábamos, menos en los indios". Estamos en el extremo opuesto de Sarmiento, para quien la naturaleza es siempre una amenaza; como para Fenimore Cooper, todo lo que rodea al viajero, es un peligro latente. El lector de Sarmiento, mientras atraviesa la pampa, no debe cerrar los ojos.

En estos capitulos, Mansilla logra convertir a un heterogéneo ejército de frontera basado en el reclutamiento forzoso (un tema que desencadenará el canto de la queja en Martín Fierro) en un lugar apropiado para el sueño colectivo. En su excursión, un conjunto de hombres felices y casi iguales avanzan en la noche con sus sueños. La expedición militar se ha convertido en un viaje de placer. A través de este desplazamiento, Mansilla encuentra una manera no doctrinaria, no explicativa, sino fuertemente estetizada de producir el deseo de lo que está del otro lado de la civilización. Al mismo tiempo, permite intuir todo lo que se pierde en el convulsionado espacio de las ciudades.

Si el lector, después de estas entregas, ha deseado fervientemente viajar en una noche sobre el lomo del caballo, dormir y soñar en él, entonces, todo lo que el texto incorpore, cuando finalmente llegue a las tolderías ranqueles, será leído de modo diferente.

El escándalo de la escritura de Mansilla, al construir el despojamiento del desierto como el lugar del deseo, no consiste en invertir la dicotomía civilización/barbarie, sino en proponer como héroe un sujeto civilizado que elige narrar la felicidad del estado de naturaleza. Un narrador que se sustrae de la ciudad civilizada para instalarse en la frontera, punto de partida del viaje hacia los ranqueles.

\section{MaNSILla, CIUdADANo dE LA FRONTERA}

Julio Ramos plantea con respecto a Una excursión a los indios ranqueles que su excentricidad relativa, su capacidad crítica se desprende del trabajo que el texto realiza sobre las normas instituidas para el relato del viaje a Europa. En este sentido es que piensa la excursión "como un deliberado viaje a la barbarie".

Creo, sí, que el viaje es deliberado. Pero Mansilla no puede "partir desde", ni "arribar a" lugares que expresen de manera pura la civilización y la barbarie. Mansilla discute con Sarmiento. No invierte su polaridad civilización/barbarie. Muestra que, aún en el momento de la escritura de Facundo, la escisión absoluta entre los dos polos era inverificable en los hechos. La dicotomía sólo podía sustentarse en una ficción sobre el otro, que para Sarmiento, por supuesto, no es el indio sino el gaucho.

Mansilla, y su texto, no parten de Buenos Aires sino de la frontera. En los capítulos iniciales de Ranqueles, podemos leer que Mansilla, en el fuerte, ya convive con casi todo lo que va a aparecer durante el viaje mismo. Un escritor contemporáneo, Santiago de Estrada, describe así a Mansilla:

Su oficina era un maremagnum de gentes de todas profesiones, desde la muy digna del sacerdocio, representada por venerables franciscanos hasta la muy productiva del comercio, encarnada en el honrado y cascarrabias proveedor de la guarnición. Le seguían unos indiazos sucios y mal cubiertos, mujeres que imploraban gracia en nombre de sus cónyuges, viejos desocupados que iban a caza de noticias y abuelas agradecidas que 
llevaban al comandante huevos y teros de avestruz. Mansilla echaba su párrafo con los franciscanos, desesperaba de encargos al proveedor, platicaba con los indios, concedía o negaba amnistía a las mujeres, sorprendía a los buenos viejos con algún episodio que los dejaba boquiabiertos, mandaba a la cocina a las viejas y, tenía tiempo para expedir la correspondencia oficial, dictar centenares de epístolas, y atender el gran pensamiento que lo preocupaba: reestablecer en primer lugar la disciplina y en segundo lugar avanzar la frontera del Río Cuarto" (Estrada).

Santiago de Estrada no tropieza por azar con esta imagen. Su texto muestra que en Buenos Aires o mejor para un público de Buenos Aires, se promociona una suerte de viaje turístico que consiste en ir a espiar al exótico coronel Mansilla en la frontera.

Es interesante retener esta imagen de Mansilla que Estrada (constituido en viajero) pone en circulación en su libro de viajes. Mansilla es mirado como un "raro", no sólo por los indios durante la excursión - lo que ya constituiría un tópico de los momentos de llegada, sino por alguien de su misma clase, de su mismo círculo. Y es mirado así, no sólo por sus extravagancias - ya conocidas - en recintos urbanos como el Club del Progreso, el lugar preferido para sus reuniones por la elite porteña, sino porque se exhibe como un ciudadano de la frontera: Mansilla está instalado en este espacio, parece conocer sus códigos y disfrutar de su estadía.

En esto también, Mansilla parece burlarse de Sarmiento. La humillación que Sarmiento, ahora Presidente de la república, le ha infligido, al enviarlo a un lejano y oscuro puesto de frontera en lugar de ofrecerle el Ministerio de guerra que Mansilla esperaba, se convierte en una estadía placentera.

Pero lo que Santiago de Estrada capta en este texto no es solamente la imagen de Mansilla, es también la complejidad de esta frontera hacia 1870. Esta frontera (como cualquier otra) es un producto histórico. En este caso, se ha generado primero por el proceso de conquista y colonización, luego por las guerras de independencia, más tarde por la guerra civil y los enfrentamientos entre unitarios y federales. En el momento de la excursión, la frontera integra y muestra los límites — cada vez más confusos- entre blancos e indios, "bárbaros "y civilizados". Hacia los "70 la frontera ha incorporado y permitido el cruce o pasaje, según los casos, de indios y blancos, unitarios y federales, extranjeros y gauchos.

Y es desde este espacio de mezcla de donde parte Mansilla. A juzgar por la descripción de Estrada, Mansilla no necesita moverse del fuerte para comer una tortilla de huevos de avestruz, delicia culinaria criolla que se muestra como uno de los objetivos explícitos del viaje en la carta a Santiago Arcos que funciona como el primer capítulo de Ranqueles. De modo que el punto de partida del viaje no es el espacio civilizado, aunque haya sido producido por el avance del hombre blanco sobre el territorio de los indios. Es un espacio donde circulan nociones diferentes del delito, de la moral y de las transacciones comerciales. El imperio de un corpus de leyes no escritas le otorga a esta frontera una autonomía relativa con respecto a la organización que el Estado nacional imprime en las ciudades y a los cacicazgos en Tierra Adentro.

Mansilla se dirige deliberadamente a un espacio en el que la barbarie ya no es absoluta. Los indios que encontrará en el viaje no son muy diferentes de los que llegan al fuerte, trafican allí con los blancos, buscan su protección circunstancial y conviven en las tolderías con cautivas blancas e hijos mestizos, con bandidos blancos que escapan de la justicia o leen 
La Tribuna, el diario donde se encontrarán retratados cuando se publique allí Ranqueles como folletín.

En las tolderías Mansilla puede, incluso, encontrarse con un antiguo condiscípulo de escuela, el Dr. Macías, enviado por los jefes militares para negociar uno de los tantos tratados de paz con los indios, alguien que se convierte primero en prisionero y luego en secretario del cacique Mariano Rosas: "las primeras cartas que yo recibí en el Río Cuarto de aquel cacique eran escritas por mi antiguo condiscípulo" escribe Mansilla exhibiendo claramente la paradoja de esta comunicación. En las cartas del cacique indio redactadas por el antiguo condiscípulo de Mansilla se toca un extremo casi impensable de la relación entre letrados y bárbaros que tendrá su antecedente más irritante en la figura del secretario del caudillo, el letrado que funcionará como asesor, como interlocutor, como escriba, como mediador entre los dos mundos. Esta figura mostrará que, del lado de la barbarie, el letrado es mano de obra empleada y retribuida con favores, de diferente tipo, pero también mostrará que los soportes de la civilización no sólo no son garantía suficiente para impedir el cruce de fronteras sino que se convierten en causa y sentido del pasaje de bandos.

La mezcla de tensión y fruición con que Mansilla narra la biografía del doctor Macías y sobre todo una de sus frases más certeras - "una secretaría hace celosos en cualquier parte, lo mismo en Berlín que en París, en Buenos Aires que en Leubucó"- dan cuenta del esfuerzo del narrador por ponerse en el lugar del otro sin abandonar nunca su lugar.

Por eso, si hay algo del libro de Sarmiento con que Ranqueles coincide es con uno de los procedimientos más notables de la construcción del Facundo. Esto es, la manera en que la biografia central de la barbarie (la de Facundo Quiroga) se trama con una serie de biografias menores, a las que denomino biografías de pasaje, porque relatan historias de vida, cuyo valor está asignado por Sarmiento a uno de los dos polos de la dicotomía, pero que en realidad, para el lector, pueden tener idéntico valor del otro lado. Se trata de historias como la del Boyero o la del mayor Navarro o incluso la del capataz de carreta, ese pequeño caudillo en viaje en cuyas manos pone el hombre civilizado su vida y sus bienes al atravesar el desierto.

\section{UNA ESTÉTICA DE LA ESPERA}

Así como la frontera - una zona intermedia, que no es ni barbarie ni civilización, en la que Mansilla se siente a gusto- es el punto de partida del texto, las diversas dilaciones a que es sometido el viajero hasta encontrarse finalmente con el cacique Mariano Rosas constituyen los capítulos predilectos del escritor. Estos capítulos que narran la espera, son también la zona fronteriza de su texto. El personaje que Mansilla se construye no es, precisamente, una víctima de la espera (una de las más importantes novelas argentinas del siglo XX, Zama, de Antonio di Benedeto, está dedicada, simplemente "A las víctimas de la espera" y de hecho el texto es el relato de una espera humillante).

Mansilla disfruta de la espera. Así, en Ranqueles, el lector tarda veinticinco capítulos en llegar a Leubucó y en la causerie "Los siete platos de arroz con leche", una visita de pocas horas a la casa de Rosas se convertirá en un viaje que ocupará tres entregas de folletín. La espera ante los indios se reitera cuando se trata de llegar a la habitación de Rosas, ya en Palermo, una llegada que se demora de cuarto en cuarto, durante horas. Rosas hace lo mismo 
que el cacique ranquel, lo hace entrar en su juego, dispone de su tiempo. Mansilla se somete voluntariamente al juego del otro: de esa tensión entre el tiempo que se le impone como detención y su propia capacidad de convertir la demora en el goce de las palabras surge lo mejor de su literatura.

"He aprendido a tener paciencia con los indios", escribe. Sin embargo, en el momento crucial en que el encuentro con el cacique está por producirse, Mansilla ya no tiene certezas: "En efecto, querido Santiago, mirando con sangre fría mi viaje a los toldos, ¿no te parece que las demoras que me ha hecho sufrir Mariano Rosas, antes de dejarme penetrar en su morada, las he merecido por mi extravagancia?".

Perder el tiempo, esperar lo que no debe esperarse, ser culpable de haber entrado en un terreno ajeno, haber insistido ante la autoridad del jefe militar para obtener el permiso de la excursión, haberse extralimitado, estar fuera de lo permitido. Todo esto está implícito en el momento de preguntarse para qué viajó.

El lector, que ha acompañado el viaje, debe, también, dudar. Mansilla maneja la debilidad de su personaje como un elemento de interés y de suspenso y, al mismo tiempo, como un problema para la escritura: éste es el momento crucial, un poco como el momento en que Borges tiene que empezar a describir el aleph, el momento en que se va a entrar definitivamente en lo otro.

Si el itinerario a Leubucó, a las tolderías del cacique Mariano Rozas, es largo, también lo es el trayecto textual hasta que se produzca, en el camino, el primer encuentro con los indios. Recién en el capítulo quince, los expedicionarios divisan, a lo lejos, al primer grupo de indios. De pronto, un indio solo se desprende del grupo. La escritura empieza a focalizar un individuo bárbaro.

El indio avanzaba hacia nosotros, haciendo molinetes con su larga lanza, adornada de un gran penacho encarnado de plumas de flamenco. Tuve la intención de detenerme, pero en la disyuntiva de que el indio creyera que lo hacía de recelo por él, preferí seguir adelante, aún exponiéndome a que, por no dejarlo acercarse bastante, no me reconociera bien.

Mansilla y el indio, avanzan en un duelo implícito: se trata de ver cuál de los dos jinetes se detendrá primero. De pronto este indio, que se aproxima haciendo molinetes con su larga lanza adornada con un gran penacho encarnado de plumas de flamenco, hace algo inesperado: "El indio sujetó su caballo y con la destreza de un acróbata se puso de pie sobre él, sirviéndole de apoyo la lanza". Y Mansilla, entonces: "Seguí avanzando, aunque cortando algo el paso. El indio continuó inmóvil. Estaríamos como a tiro de fusil de él cuando, cayendo a plomo sobre el lomo del caballo, partió a toda rienda en mi dirección, pero con el intento visible de que no nos encontráramos".

Se trata nuevamente, de un desplazamiento escandaloso: el primer indio con el que Mansilla se topa es un indio acróbata, un indio exhibicionista que posa frente a él del mismo modo que Mansilla se desprende de la tropa, para ir a posar frente a la figura del indio que se acerca, solitaria. En el primer encuentro entre civilización y barbarie que el texto ofrece no hay violencia, tampoco palabras, sólo gestos que definen el reconocimiento recíproco de dos hombres.

La escena carece de importancia para la expedición militar y no agrega ningún conocimiento útil. Lo que importa es cómo funciona el encuentro en el relato: en medio 
de la franja borrosa que separa al fuerte militar de Tierra Adentro, siguiendo con dificultad la rastrillada, esquivando el guadal, sonando por las noches, este hombre ha venido a posar frente a otro, que se le diferencia. La imagen resulta contemporánea porque algunos textos de la literatura argentina contemporánea reescriben escenas de estos primeros encuentros produciendo desplazamientos tan escandalosos como el de esta escena de Mansilla. Aira, por un lado con su vertiente emplumada del desierto y su Ema la cautiva convertida en empresaria; Saer, por el otro, con El entenado, que fija el momento en que los indios, uno por uno, se acercan al narrador para dejar grabada, en su memoria, su recuerdo. Este primer indio con el que el texto se topa pareciera decir al narrador, como los indios de Colastiné al entenado: Cuando te vayas me recordarás como el indio que galopaba a tu encuentro haciendo molinetes con la lanza adornada de plumas rojas y que poco antes de toparte se paró sobre el caballo en un equlibrio tan delicado como inútil.

\section{ObRas citadas}

Estrada, Santiago. Viajes [1889]. Buenos Aires: Estrada, 1946.

Mansilla, Lucio V. Una excursión a los indios ranqueles [1870]. México, Buenos Aires: Fondo de Cultura Económica, 1947.

Pratt, Mary Louise. Travel Writing and Transculturation. London and New York: Routledge, 1992.

Ramos, Julio. Desencuentros de la modernidad en América Latina. Literatura y política en el siglo XIX. México: Fondo de Cultura Económica, 1989.

Viñas, David. Indios, ejército y frontera. México: Siglo XXI, 1982. 